\title{
BMJ Open Assessing knowledge and self-report intention from COVID-19 symptoms based on the Health Belief Model among international students in Heilongjiang, China: a cross- sectional study
}

\author{
Omar Yacouba Ismael (D) , ${ }^{1}$ Yuanheng Li, ${ }^{1}$ Zhuowa Sha, ${ }^{1}$ Qunhong Wu, ${ }^{2}$ \\ Lifeng Wei, ${ }^{3}$ Mingli Jiao (i) , ${ }^{1}$ Ye Li (i) , ${ }^{2}$ Linghan Shan, ${ }^{2}$ Yushu Wang ${ }^{1}$
}

To cite: Ismael OY, Li Y, Sha Z et al. Assessing knowledge and self-report intention from COVID-19 symptoms based on the Health Belief Model among international students in Heilongjiang, China: a crosssectional study. BMJ Open 2022:12:e050867. doi:10.1136/ bmjopen-2021-050867

- Prepublication history and additional supplemental material for this paper are available online. To view these files, please visit the journal online (http://dx.doi.org/10.1136/ bmjopen-2021-050867).

$\mathrm{OYI}, \mathrm{YL}$ and YW contributed equally.

Received 03 March 2021 Accepted 30 November 2021

Check for updates

(c) Author(s) (or their employer(s)) 2022. Re-use permitted under CC BY-NC. No commercial re-use. See rights and permissions. Published by BMJ.

For numbered affiliations see end of article.

Correspondence to

Dr Mingli Jiao;

minglijia0@126.com

\section{ABSTRACT}

Background A COVID-19 outbreak has been contained in China through effective prevention measures with the collaboration of the citizens. However, there is resistance to self-reported symptoms as required in the international student community. This study explored knowledge level and symptoms reporting behaviours toward COVID-19 among international students.

Methods An online cross-sectional investigation was conducted among 119 international students across Heilongjiang province and questionnaires implemented through WeChat between 1 and 25 March 2020. The results were explained using descriptive $\mathrm{X}^{2}$ test and binary logistic regression analysis using SPSS V.20.

Results In total, 119 international students participated, with a response rate of $90.16 \%$. Of the 119 respondents, 96 (80.7\%) knew COVID-19 symptoms, 109 (91.6\%) took cognisance of questions on the importance of the maintenance of wearing masks and $113(95 \%)$ on questions regarding hand hygiene in the prevention of disease transmission. However, results show that there were still large gaps in knowledge about questions regarding the virus and the treatment methods (many participants incorrectly believed that the virus could be kill by drinking alcohol or smoking). In addition, more than half of the participants declared compliance with positive health behaviours, however $27.7 \%$ did not agree with vaccination (if any), and $31.1 \%$ did not agree to be quarantined after being diagnosed with COVID-19. Furthermore, 20 participants $(16,80 \%)$ expressed an inclination to deliberately withhold symptoms. Variables in the Health Belief Model showed a significant association with behavioural change.

Conclusion From our study, we found that there is evident knowledge about COVID-19 among international students, although orientation and sensitisation are still required. Those who were aware of the benefits of reporting, the severity of COVID-19 and the legal consequences of deliberately concealing information showed a greater willingness to report; conversely, those who believed reporting is very inconvenient and feared
Strengths and limitations of this study

- A cross-sectional study is limited in its usefulness in capturing this type of dynamic change. Future research may consider a longitudinal design.

- Due to the small sample size, considering the cost and convenience of conducting research, this study only selectively investigated one province that may limit the generalisability of this study's findings. In addition, the small sample size limits the number of independent variables that can be included in multivariate analyses, and analyses were generally only able to detect large effects.

- The urgency of the situation causes some limitations in the study.

- Despite the limitations, this study addressed a major health problem and highlighted the area where no research has been done. The findings of this study would be critical to design effective control measures of COVID-19 in an outbreak.

being quarantined after reporting showed less willingness to report. A study focusing on international students' knowledge and behaviour amid the pandemic will provide information for countries to cut off the chain of disease transmission of all variants of COVID-19.

\section{BACKGROUND}

The ongoing COVID-19 is a serious public health issue in the world. Consequently, the study on the spread mechanisms and prevention and control strategies of COVID-19 has become a global problem to be solved.

Moreover, as has been demonstrated in previous pandemics, lack of proper knowledge about the disease is associated with negative behaviours among people, which can further complicate efforts to prevent 
the spread of the disease. It is therefore imperative that communities be equipped with knowledge and healthy behaviours to limit the impact of COVID-19.

With the deepening of China's openness and the 'Belt and Road' policy, the number of international students studying in China has been increasing. As part of its socioeconomic development, China has jumped from being the largest exporter of international students to the third largest recipient. Therefore, when encountering public health emergencies, international students have become an important part of the community, and it is extremely important for them to effectively deal with the epidemic. In order to avoid cases of imported infections, schools banning students to return to China if they were abroad and those who remained in China should adhere to the epidemic prevention measures and have been asked for an early detection of cases, to report daily if they feel symptoms of COVID-19 such as fever, cough, runny noses, etc. However, since the COVID-19 outbreak, many international students did not cooperate with community epidemic prevention and control measures. As resistance to cooperation has grown, the Chinese authorities have taken more drastic control and preventive measures, including restricting the movement of people in cities and communities, rewarding those who provide clues to withholders and facilitating systematic and comprehensive searches through communities.

In situations such as these, evidence-based public health frameworks can provide a useful temporary measure. One such framework is the Health Belief Model (HBM). The HBM was originally developed to study why patients may not seek screening for tuberculosis,,${ }^{12}$ and is one of the most prominent public health frameworks for understanding why individuals may or may not act in the face of a threat to personal or community health. The HBM has been used for decades to study vaccination, medication adherence, diabetes self-care, condom use and other behaviours that require modification of a patient's actions to mitigate a threat to health. Broadly speaking, HBM believes that direct cues from an individual's beliefs and actions can guide behaviour. Beliefs, in turn, are determined by one's background, including one's impressions of perceived threats, perceived benefits of taking action, perceived barriers to taking action and perceived ability to take action (ie, perceived self-efficacy). ${ }^{3}$

Given all these concerns, the observance of preventive health standards and behaviours in society is essential to better control the disease. Numerous research studies are being conducted on COVID-19, but this article is the first to highlight this area. Additionally, a study focusing on international students' knowledge and behaviour amid the pandemic will provide information for countries to cut off the chain of disease transmission of all variants of COVID-19. To our knowledge, the HBM variables chosen have not yet been tested on the international students in Heilongjiang. We anticipate that our findings will explain factors that may contribute to a responsible preventive health behaviour. Therefore, this study's goals were as follows: (1) to examine the level of knowledge of international students towards COVID-19; (2) to elucidate and analyse the student's beliefs associated with self-reporting of symptoms; (3) to provide effective suggestions and measures for encouraging the students to report if symptoms of pneumonia occur. In addition, this study tested the following hypotheses: (1) perceived susceptibility and severity of COVID-19 infection will be positively associated with healthy behaviour such as COVID-19 symptoms self-reporting; (2) perceived benefits of reporting symptoms will be positively associated with willingness to early report if related symptoms of pneumonia occur; (3) perceived barriers to self-report symptoms will be negatively associated with willingness to self-report.

\section{MATERIALS AND METHODS \\ Setting}

Heilongjiang province is located along the northeast border of China. It covers an area of over $460000 \mathrm{~km}^{2}$, and has a population of 37.68 million. According to the Department of Education update, in 2019 Heilongjiang province accounted 13429 international students. In March 2020, Heilongjiang had become the province with the highest diagnosed patients in China (ie, even worse than Hubei province). By 11 March 2020, according to the Chinese Journal of Epidemiology, a total of 482 domestic cases of COVID-19 was reported in Heilongjiang and most of cases were imported. The incidence rate of COVID-19 was relatively high and the early epidemic was serious in Heilongjiang; the number of cases was high in clusters especially family clusters. ${ }^{4}$ Because of this information, we selected Heilongjiang for this study.

\section{Questionnaire design}

After conducting the necessary literature research and receiving expert advice, we developed a self-administered questionnaire (online supplemental file 1). To confirm the effectiveness of the questionnaire, we invited experts from fields such as health emergency, epidemiology and public psychology, as well as three health administration workers who are currently in charge of epidemic prevention and control, to engage in two rounds of reviews of the questionnaire. They responded to the entire questionnaire and again 2 weeks later. The data obtained were not used for the final analysis. This questionnaire included the following parts: (1) sociodemographic information; (2) knowledge of respondents; (3) willingness and beliefs associated with reporting symptoms; (4) possibility of investigation of healthy behaviour. The dependent variable in this study was the respondents' self-rated willingness to report if related symptoms of pneumonia exist, which was evaluated by the item: 'If related symptoms occur, how likely are you to report or go to a designated medical institution?' using a 5-point Likert scale ranging from 1 to 5 (definitely would not report, would not report, unsure, would report, definitely would report). During analysis, for the purpose of comparing respondents who 
had a positive willingness toward reporting with those who did not, we sorted those who selected 4 and 5 into the category 'report', and those who selected 1, 2, and 3 into the category 'not report'.

Sociodemographic data were collected, including the respondents' gender, age, education level, medical and non-medical student, marital status, living arrangement and religious belief. Among them, the religious belief data were obtained by the item: 'Do you have a religion', using yes or no as the answer option.

The questions that address the knowledge of students as well as the HBM components for the current study were adapted from the information available in published articles.

The level of knowledge regarding COVID-19 of the international students was assessed in which yes, no or don't know option was given against each set of questions. The knowledge was assessed by nine factual statements included in the questionnaire such as about the disease, its nature and mode of transmission, symptoms of the disease, specific treatment, preventive measures, quarantine and social distancing. To better understand what international students' knowledge of COVID-19 was, participants were asked questions such as: Do you know the cause of this pneumonia in Wuhan?; Do you know the symptoms of this pneumonia in Wuhan?; How did COVID-19 infection spread? Response categories were yes, no and don't know. Additionally, a Likert scale was used to which they indicated their degree of agreement by selecting a rating between 1 and 5 . For data analysis, only yes and no responses were examined.

Based on the $80 \%-100 \%$, correct answer for each question was considered as appropriate knowledge and below
$80.0 \%$ was considered as inappropriate knowledge. Similarly, healthy behaviours were also categorised.

The respondents' beliefs associated with reporting symptoms were assessed through the construct of HBM, to which they indicated their degree of agreement by selecting a rating between 1 (strongly disagree) and 5 (strongly agree). To test the internal consistency of the HBM components, Cronbach's alphas were computed for each subscale as described in table 1 . The respondents' overall perceptions of reporting symptoms and the COVID-19 infection were evaluated by the following prompts:

In the questionnaire, we also designed items to investigate healthy behaviours which would promote respondents to report, in other words the likelihood of respecting the prevention and control measures. We investigated healthy behaviour in which a 5-point Likert scale was given against each set of questions. This variable was measured by 15 items that were designed to assess the possibility that a participant would comply with the prevention and control measures toward COVID-19. The positive healthy behaviour parameters included effectiveness of mask use, hand washing, social distancing in preventing the disease, etc. The Cronbach's alpha coefficient was 0.96

During analysis, all responses to the prompts were converted into binary variables: respondents who rated 4 and 5 were sorted into the category 'agree', whereas respondents who rated 1, 2, and 3 were sorted into the category 'disagree'.

\section{Sample and data collection}

The cross-sectional study was carried out in the format of an anonymous web-based questionnaire. The

Table 1 Measurements of items in the construct of HBM

\begin{tabular}{|c|c|}
\hline Construct & Items \\
\hline $\begin{array}{l}\text { Perceived } \\
\text { severity }\end{array}$ & $\begin{array}{l}\text { Measured by nine items that were designed to help participants assess the severity of COVID-19 and } \\
\text { understand their personal feelings. These items included questions about whether the disease caused } \\
\text { serious impact on daily life, and the effects on the patient and the family of the patient. The Cronbach's } \\
\text { alpha coefficient was } 0.85\end{array}$ \\
\hline $\begin{array}{l}\text { Perceived } \\
\text { barriers }\end{array}$ & $\begin{array}{l}\text { Measured with } 12 \text { items intended to help participants to assess the barriers that prevented them from taking } \\
\text { action to undergo a self-report after having pneumonia symptoms. The Cronbach's alpha coefficient was } \\
0.85\end{array}$ \\
\hline Self-efficacy & $\begin{array}{l}\text { Measured by three items aimed at determining whether participants were confident that, under special } \\
\text { circumstances, they could overcome the barriers to undergoing a consultation or report. The Cronbach's } \\
\text { alpha coefficient was } 0.69\end{array}$ \\
\hline
\end{tabular}


questionnaire was in English and it was pretested among a cross-section of participants to ensure the clarity of questions and eliminate the ambiguity. The questionnaire survey was conducted among international students of Heilongjiang province. We have sent a link to the questionnaire to the residents in their communities through social networking software such as WeChat (WeChat is the largest social media platform in China similar to Facebook and Twitter, and the number of monthly active accounts has reached to 1.165 billion)..$^{5}$ Only international students located in Heilongjiang during the pandemic were considered eligible to take part in this study. It has been asked not make duplication if he or she already responded. Alongside an explanation of the study's intention and anonymity, those who received the link could voluntarily decide whether to respond or not. Exclusion criteria included unwillingness, living outside of Heilongjiang and sickness. The data were collected between 1 and 25 March 2020. A purposive sampling technique was adopted to obtain the sample. Finally, according to the questionnaire network platform, 132 people (international students) clicked on the link and 119 responded to the questionnaire (potential response rate $=90.15 \%$ ).

\section{Data analysis}

Collected data were cross-checked and cleaned. Except for age, all our variables are categorical and those with non-normal distributions were recoded. To quickly visualise the distribution, the graph is approximately bell shaped and symmetric about the mean. Therefore, we have proceeded to a parametric test. Missing data were checked and none was recorded for variables.

Once data collection was completed, the questionnaire was reviewed to ensure that all quantitative questions were answered and that each question had no more than one answer unless stated otherwise. Data screening and verification were performed. Using the questionnaire guide, the data were then entered into SPSS (IBM, V.2010). Data analyses included descriptive $\mathrm{X}^{2}$ test and regression analyses. First, descriptive statistics were used to summarise data collected for sociodemographic variables, COVID-19 knowledge and COVID-19 healthy behaviours. Percentages were calculated for these variables. Furthermore, frequencies were run to examine the distribution of sociodemographic, reporting behaviour and HBM items (eg, perceived susceptibility, severity, benefits, barriers and cues to action).

Next, logistic regression analyses were conducted to determine the relationship between sociodemographic variables, HBM component and reporting behaviour (will report/will not report).

SPSS V.20 was used to conduct the analysis. Statistical significance was set at $\mathrm{p}<0.05$.

\section{Patient and public involvement}

No patient involved in this study. Study participants were not involved in the setting of the research questions or study design. Additionally, study finding will be disseminated among the participants.

\section{RESULTS}

\section{Characteristics of the respondents}

First, descriptive statistics were used to summarise data collected for sociodemographic variables. More than half of the respondents $(79.0 \%)$ were men. The ages of the respondents were concentrated between 21 and 30 years old $(58.0 \%)$. Among the respondents, $76.5 \%$ had an education level of master's degree or above, and $37 \%$ were medical students. The vast majority of the respondents $(74.48 \%)$ were Muslims, and $42.9 \%$ lived alone. Of the result, $85.7 \%$ are black people while $4.2 \%$ are white and $10.1 \%$ are Asian. A proportion of $16.80 \%$ of the respondents chose not to report when they had related symptoms of pneumonia, and $83.19 \%$ chose to report. A total of $18.08 \%$ of men chose not to report, which was higher than that of women $(12 \%)$. Respondents aged 21-30 years had the highest non-reporting rate (12.79\%). In terms of education level, the proportion of people who chose not to report was the highest among those with master's degree and above (18.68\%), but the lowest among those with high school and below education level $(18.68 \%)$. Single respondents had a higher percentage of non-reporting (20.48\%) than those who were married. The proportion of people who chose not to report was among the respondents living with others (33.33\%), which was higher than those living alone $(17.64 \%)$ and living with family or friends $(18.18 \%)$. Table 2 displays correlation between sociodemographic variables and willingness to report to the doctor if symptoms of pneumonia occur.

\section{COVID-19 knowledge among international students}

Next, to assess the knowledge of students, we found a total of 94 participants $(80 \%)$ who answered the utility to reduce assembly. Additionally, the vast majority of 109 participants $(91.6 \%)$ agreed that wearing masks is useful. Of the result, 96 respondents $(80.7 \%)$ answered knowing the symptoms of COVID-19 and 105 (88.2\%) agreed that quarantine is necessary. Almost all of the respondents, $113(95 \%)$, think that regularly washing hands is useful. However, the study showed that poor knowledge was more apparent in response to questions regarding virus and the treatment methods. Many participants (more than $30 \%$ ) incorrectly believed that the virus could be killed by drinking alcohol or smoking. It is noteworthy to state that this study did not find a significant association between knowledge and behavioural change.

Based on the $80 \%-100 \%$ correct answer for each question was considered as appropriate knowledge, and below $80.0 \%$ was considered as inappropriate knowledge. Figure 1 and table 3 describe the current status of COVID-19 knowledge among international students.

\section{COVID-19 healthy behaviour}

To verify healthy behaviour among respondents, of the result $74.8 \%$ and $77.8 \%$, respectively, agreed to declare 
Table 2 Sociodemographic characteristics of respondents $(n=119)$

\section{If related symptoms occur, how likely would you go to a designated hospital?}

\begin{tabular}{|c|c|c|c|c|}
\hline & $\begin{array}{l}\text { I will not go to the hospital } \\
(\mathrm{N}=20)\end{array}$ & $\begin{array}{l}\text { I will go to the hospital } \\
(\mathrm{N}=99)\end{array}$ & $\mathbf{N}$ & $P$ value \\
\hline Gender & & & & 0.083 \\
\hline Male & 17 (18.08) & 77 (81.9) & $94(79)$ & \\
\hline Female & $3(12)$ & $22(88)$ & $25(21)$ & \\
\hline Age & & & & 0.003 \\
\hline$\leq 20$ & $0(0.00)$ & $1(100)$ & $1(0.84)$ & \\
\hline $21-30$ & $16(23.18)$ & $53(76.81)$ & 69 (57.98) & \\
\hline $31-40$ & $4(8.7)$ & $42(91.30)$ & $46(38.65)$ & \\
\hline $41-50$ & $0(0.00)$ & $2(100)$ & $2(1.68)$ & \\
\hline$\geq 51$ & $0(0.00)$ & $1(100)$ & $1(0.84)$ & \\
\hline Education level & & & & 0.068 \\
\hline High school and below & $0(0.00)$ & $4(100)$ & $4(3.36)$ & \\
\hline Bachelor's degree & $3(12.5)$ & $21(87.5)$ & $24(20.16)$ & \\
\hline Master's degree and above & $17(18.68)$ & 74 (81.31) & $91(76.47)$ & \\
\hline Major & & & & 0.091 \\
\hline Medical student & $7(15.90)$ & 37 (84.09) & $44(36.97)$ & \\
\hline Non-medical student & $13(17.33)$ & $62(82.66)$ & 75 (63.02) & \\
\hline Living situation & & & & 0.097 \\
\hline Live alone & $9(17.64)$ & $42(82.35)$ & $51(42.85)$ & \\
\hline Live with family or friends & $4(18.18)$ & $18(81.81)$ & $22(18.48)$ & \\
\hline Live with roommate & $5(12.5)$ & $35(87.5)$ & $40(33.61)$ & \\
\hline Live with others & $2(33.33)$ & $4(66.66)$ & $6(5.04)$ & \\
\hline Marital status & & & & 0.076 \\
\hline Married & $3(8.33)$ & $33(91.66)$ & 36 (31.57) & \\
\hline Single & $17(20.48)$ & 66 (79.51) & $83(72.80)$ & \\
\hline
\end{tabular}

regarding a history of close contact and history of living in high-risk areas. Overall, $91.5 \%$ of respondents accepted and believed that wearing masks would prevent chances of contracting COVID-19; however, $22.8 \%$ of the respondents disagreed to dial the emergency number for consultation or report if related symptoms occur. Other percentages, $84.9 \%$, agreed to have a good and safe eating habit and $56.3 \%$ agreed to work out. In addition, $77.3 \%$ of the respondents expressed agreement to take temperature regularly. In contrast, overall, nearly one-fourth of the respondents $(27.7 \%)$ did not agree to get a vaccine if available and $31.1 \%$ did not agree to be isolated if diagnosed with COVID-19. Figure 2 displays the promotion of healthy behaviours, the cues that investigate whether or not students adopt a healthy behaviour during the COVID-19 outbreak.

Domains of the HBM correlated with the willingness to go to hospital if related symptoms of pneumonia occur

Students' perceptions were collected and explained in the framework of HBM. Data have been collected based on the ranking from 1 to 5 (completely agree to completely disagree), and median ranks obtained using Friedman's test were used to divide the responses into two (agree and disagree) for easy description. Of the respondents, about $20 \%$ believed that they had some or high chance of getting COVID-19. Regarding the perceived severity of the disease, there was clear awareness of the impact of COVID-19 on all domains of life. Indeed, more than half $(61.34 \%)$ agreed that COVID-19 would affect social life and $71.42 \%$ agreed that COVID-19 will affect their work. Comparably for the domain of benefit, the majority, more than half $(57.98 \%)$, agreed that early consultation and report would detect the disease early; $56.30 \%$ agreed that timely consultation if symptoms discovered could help recover quickly and $69.74 \%$ agreed that timely consultation and report can prevent the spread of the virus. Among the potential barriers to reporting and consultation, the unwillingness and fear of finding out that they had COVID-19 were reported by more than $40 \%$ of respondents. Those who are willing to report were significantly more likely to have fears about discovering they had the disease than the opposite group. In addition, about $13 \%$ of respondents agreed that reporting 


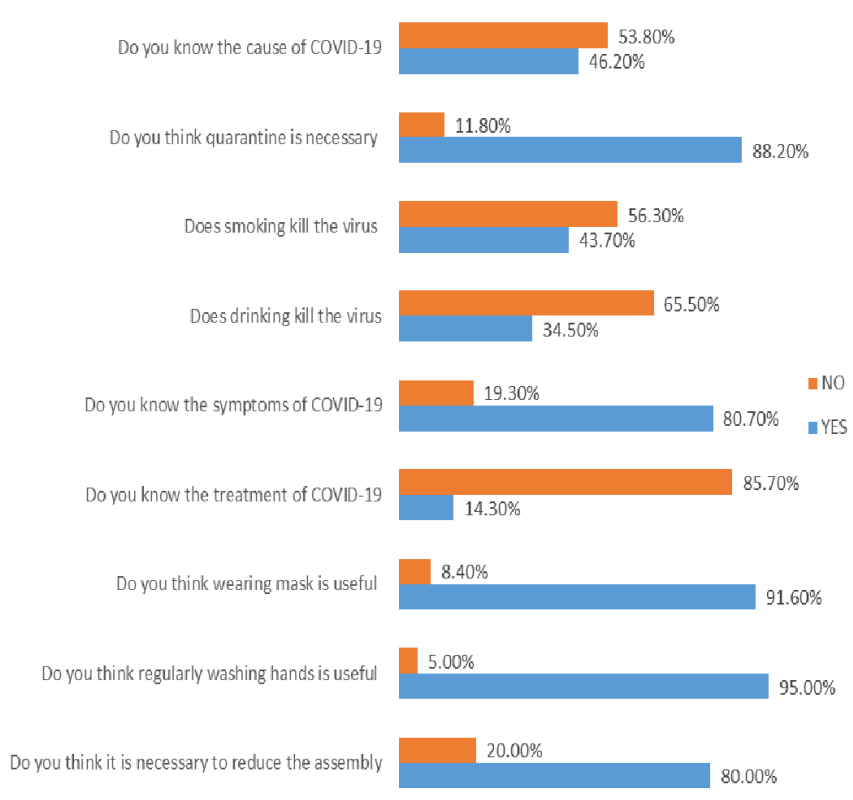

Figure 1 COVID-19 knowledge of international students.

is inconvenient. Finally, when cues to action were assessed, the majority $(55.46 \%)$ agreed to go to the hospital on time to prevent their symptoms from getting worse, $67.22 \%$ agreed to report or go to the hospital on time for advice of the health professional, and $53.78 \%$ agreed to report to the healthcare professional because concealing information will be punished by laws and regulations. Domain of selfefficacy showed that less than half $(38.65 \%)$ of participants agreed to take the time to report to the doctor and $65.54 \%$ were confident that they will go to the clinic to report if symptoms discovered. In summary, the results indicated that most respondents had relatively high perceived severity, perceived benefits, cue to action and perceived self-efficacy, but lower perceived susceptibility and barriers. The correlation analysis indicated that all domains in the HBM except perceived susceptibility had significant effects on preventive behaviours from COVID-19 $(\mathrm{p}<0.05)$. In other words, perceived susceptibility was not associated with reporting

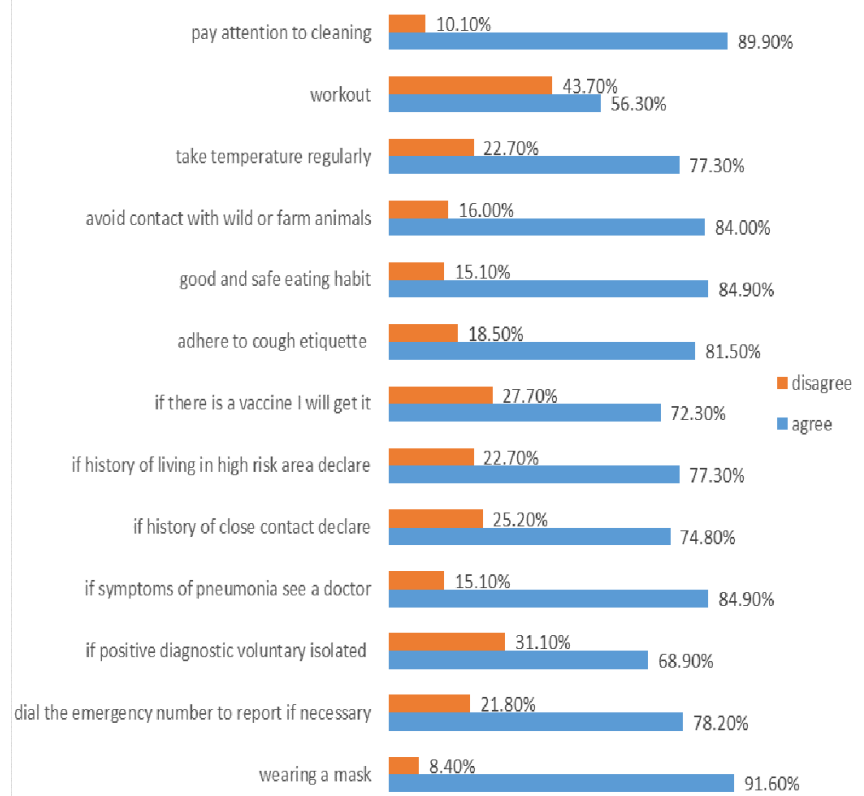

Figure 2 Promotion of healthy behaviours among international students.

symptoms. In contrast, perceived severity was significantly associated with symptoms reporting. The results partially support hypothesis 1 . The results of the test of hypothesis 2 showed that perceived benefits were significantly associated with symptoms reporting. Similarly, perceived barriers were significantly associated with reporting symptoms. Therefore, the findings provide support for hypotheses 2 and 3.

Table 4 displays the factors that are significantly correlated with a willingness to report if related symptoms of pneumonia occur.

\section{Adjusted ORs and the $p$ value of reporting in the binary} logistic regression analysis

Logistic regression analyses were conducted to determine the relationship between sociodemographic variables and reporting behaviour (will report/won't report). Unstandardised regression coefficients $(\beta)$ and ORs were performed. Statistical significance was set at 0.05 or less

Table 3 Assessment of knowledge $(\mathrm{N}=119)$

\begin{tabular}{|c|c|c|c|}
\hline Area of knowledge & $\begin{array}{l}\text { Correct } \\
\text { answer }\end{array}$ & $\begin{array}{l}\text { Appropriate knowledge } \\
\text { f (\%) }\end{array}$ & $\begin{array}{l}\text { Inappropriate knowledge } \\
\text { f (\%) }\end{array}$ \\
\hline Do you know the cause of COVID-19? & Yes & $55(46.2)$ & $64(53.8)$ \\
\hline Does smoking kill the virus? & No & $67(56.3)$ & $52(43.7)$ \\
\hline Does drinking kill the virus? & No & $78(65.5)$ & $41(34.5)$ \\
\hline Do you think wearing masks is useful? & Yes & $109(91.6)$ & $10(8.4)$ \\
\hline Do you think regularly washing hands is useful? & Yes & $113(95)$ & $6(5)$ \\
\hline Do you think it is necessary to reduce the assembly? & Yes & $94(80)$ & $25(20)$ \\
\hline
\end{tabular}


Table 4 Beliefs associated with reporting if symptoms of pneumonia occur $(n=119)$

\section{If related symptoms occur, how likely would you} go to a designated hospital?

\section{I will not go to the I will go to the hospital}

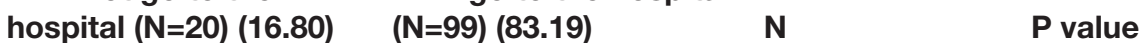

I will definitely get COVID-19.

$\begin{array}{lrrr}\text { Disagree } & 18(16.98) & 88(83.01) & 106(89.07) \\ \text { Agree } & 2(15.38) & 11(84.61) & 13(10.92)\end{array}$

I am more susceptible to get COVID-19.

$\begin{array}{lccr}\text { Disagree } & 18(18.94) & 77(81.05) & 95(79.83) \\ \text { Agree } & 2(8.33) & 22(91.66) & 24(20.16)\end{array}$

I never worry about getting COVID-19.

$\begin{array}{lrrr}\text { Disagree } & 16(17.39) & 76(82.60) & 92(77.31) \\ \text { Agree } & 4(14.81) & 23(85.18) & 27(22.68)\end{array}$

The infection is very serious in my area.

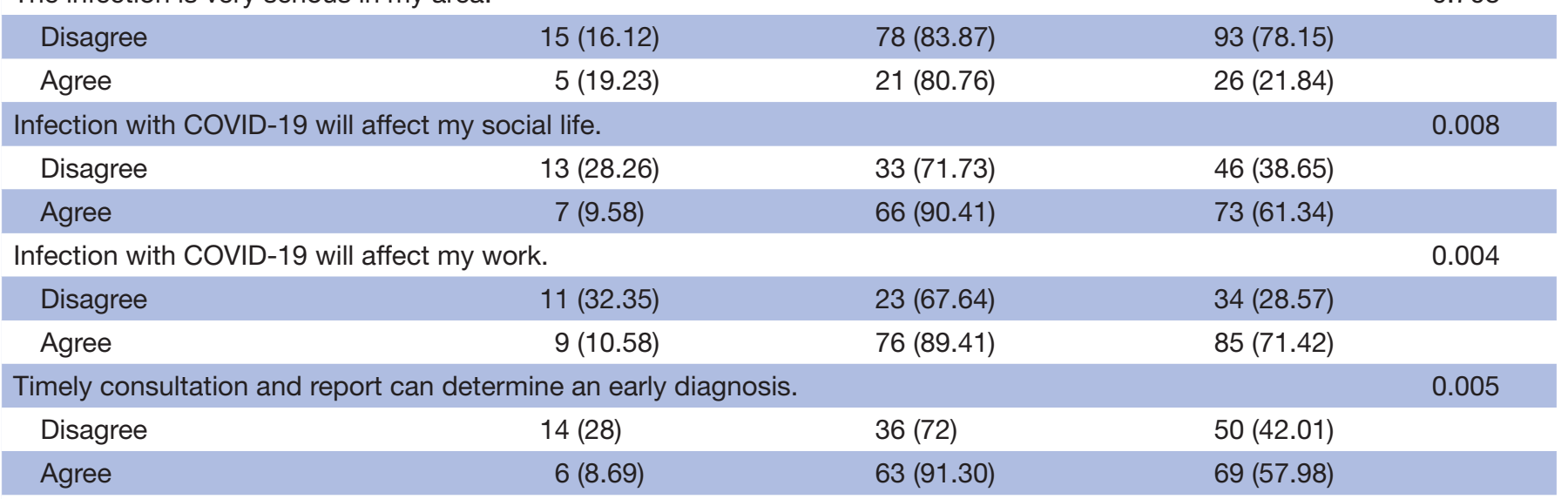

Timely consultation and report will help me to quickly recover after infection.

$\begin{array}{lccr}\text { Disagree } & 15(28.84) & 37(71.15) & 52(43.69) \\ \text { Agree } & 5(7.46) & 62(92.53) & 67(56.30)\end{array}$

Timely medical report can prevent the spread of the virus.

\begin{tabular}{|c|c|c|c|c|}
\hline Disagree & $11(30.55)$ & $25(69.44)$ & $36(30.25)$ & \\
\hline Agree & $9(10.84)$ & $74(89.15)$ & $83(69.74)$ & \\
\hline \multicolumn{4}{|l|}{ Reporting is very inconvenient. } & 0.017 \\
\hline Agree & $6(37.5)$ & $10(62.5)$ & $16(13.44)$ & \\
\hline \multicolumn{4}{|c|}{ I am scared to know that I have COVID-19. } & 0.270 \\
\hline Agree & $7(12.72)$ & $48(87.27)$ & $55(46.21)$ & \\
\hline \multicolumn{4}{|c|}{ If I have COVID-19,I would rather not punished by laws and regulations know it. } & 0.920 \\
\hline Disagree & $17(16.66)$ & $85(83.33)$ & $102(85.71)$ & \\
\hline Agree & $3(17.64)$ & $14(82.35)$ & $17(14.28)$ & \\
\hline \multicolumn{4}{|c|}{ I will go to the hospital on time for advice of the health professional. } & 0.001 \\
\hline Disagree & $13(33.33)$ & $26(66.66)$ & $39(32.77)$ & \\
\hline Agree & $7(8.75)$ & $73(91.25)$ & $80(67.22)$ & \\
\hline
\end{tabular}

Continued 
If related symptoms occur, how likely would you go to a designated hospital?

\begin{tabular}{ll}
\hline I will not go to the & I will go to the hospital \\
hospital $(\mathrm{N}=20)(16.80)$ & $(\mathrm{N}=99)(83.19)$
\end{tabular}

$\mathbf{N}$

$P$ value

\begin{tabular}{|c|c|c|c|c|}
\hline \multicolumn{5}{|c|}{$\begin{array}{l}\text { Because concealing the illness, travel history and close contact history of the diagnosed person will be punished by } 0.019 \\
\text { laws and regulations, I will report to the doctor on time. }\end{array}$} \\
\hline Disagree & $14(25.45)$ & $41(74.54)$ & $55(46.21)$ & \\
\hline Agree & $6(9.37)$ & $58(90.62)$ & $64(53.78)$ & \\
\hline \multicolumn{4}{|c|}{ I can take the time to report to the doctor. } & 0.060 \\
\hline Disagree & $16(21.91)$ & $57(78.08)$ & $73(61.34)$ & \\
\hline Agree & $4(8.69)$ & $42(91.30)$ & $46(38.65)$ & \\
\hline \multicolumn{4}{|c|}{ I am confident that I will go to the clinic to report. } & 0.034 \\
\hline Disagree & $11(26.82)$ & $30(73.17)$ & $41(34.45)$ & \\
\hline Agree & $9(11.53)$ & $69(88.46)$ & $78(65.54)$ & \\
\hline \multicolumn{4}{|c|}{ Even if I encounter difficulties, I will go to the clinic to report. } & 0.015 \\
\hline Disagree & $12(27.90)$ & $31(72.09)$ & $43(36.13)$ & \\
\hline Agree & $8(10.52)$ & $68(89.47)$ & 76 (63.86) & \\
\hline
\end{tabular}

and a CI of $95 \%$ for all analyses. Binary logistic regression analysis considering behavioural change as outcome variable explains the role of HBM variables in terms of crude and adjusted ORs.

As noted earlier, the sample size for this study was small $(\mathrm{n}=119)$. Despite this limitation, the analyses helped identify factors that may be associated with perceptions of risks and reporting behaviours related to COVID-19. When all potential explanatory variables were included in the final model, the following variables remained significantly associated with the dependent variable. The age of the respondents, perceived barriers (reporting is very inconvenient) and self-efficacy (perceived confident to report or go to the clinic) were positively associated with the dependent variable (reporting if related symptoms).

In contrast, perceived benefit, perceived susceptibility and severity were not associated with reporting symptoms. Although these variables were not significant, the relationships are worth noting and perhaps need to be further examined with a larger sample.

Thus, this study may help fill a significant gap in knowledge about barriers to COVID-19 reporting among international students and provides direction for future quantitative research with larger samples.

Table 5 shows the adjusted ORs and the $p$ value of reporting in the binary logistic regression analysis.

\section{DISCUSSION}

This descriptive, cross-sectional study was conducted among 119 participants through an online selfadministered questionnaire. So far, to the best of our knowledge, there are no previous reports of similar studies, particularly one that examined the international students' knowledge and behaviours towards COVID-19.
Therefore, we could not directly compare our results with those of other studies. In addition, it should be noted that this study was conducted in the middle and early stages of the COVID-19 outbreak in China.

Our study evaluated the knowledge and willingness associated with going to hospital or reporting if related symptoms of pneumonia are discovered among international students still remaining in Heilongjiang during the COVID-19 pandemic as well as the correlation between their behaviours towards the prevention and control measures.

The findings of this study showed good level of knowledge towards COVID-19 as demonstrated in table 3 . Moreover, as shown in figure 1, the most number of correct responses was gathered from the question about the symptoms of COVID-19 followed by the question on the maintenance of wearing masks and hand hygiene in the prevention of disease transmission. These findings were very encouraging as it is known that the lack of hygiene maintenance could lead to increase in morbidity and mortality of the deadly virus like MERS-CoV (Middle East Respiratory Syndrome Coronavirus) ${ }^{6}$ These results are in line with a study conducted in Henan which showed that $89 \%$ of healthcare workers had sufficient knowledge of COVID-19. ${ }^{7}$ However, many had inaccurate knowledge that smoking or drinking can kill the virus, indicating the need for behavioural change communication. Knowledge is the premise of establishing prevention belief, forming a positive attitude and promoting positive behaviour. Individuals' cognition and attitude toward the disease affected the effectiveness of coping strategies and behaviours to a certain extent. ${ }^{8}$ Poor knowledge can be considered as a barrier for behavioural change. This may explain the report refusal behaviour by resorting to 
Table 5 Binary logistic regression analysis of factors affecting the willingness to report if related symptoms of pneumonia occur

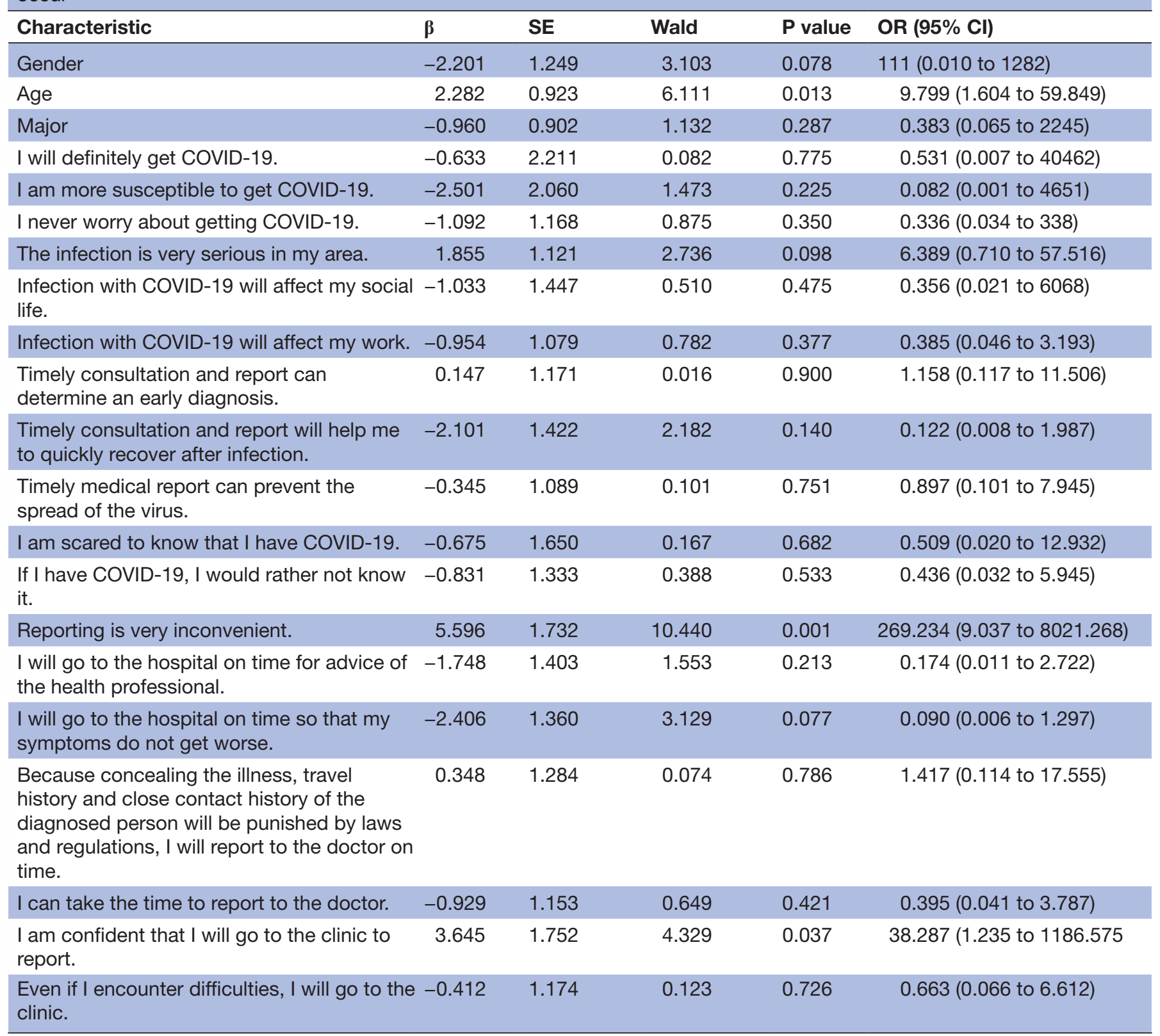

self-medication and symptoms concealment. One could also speculate that these results may be due to the media emphasis on symptoms and prevention in their awareness programme. Therefore, greater awareness of COVID-19 myth busters is crucial. This again highlights the possibility that respondents were not thoroughly briefed about COVID-19 outbreak by the relevant authorities through the media or other channels of information easily accessible for foreigners including international students in China. Therefore, our findings were a bit disappointing. Greater encouragement from health authorities is needed to assimilate COVID-19-related knowledge among students. This suggests that tapping on the network of international students will be a potentially useful method in getting across awareness of COVID-19 prevention and control measures. Further studies are needed to elucidate these factors.

Furthermore, a proportion of $16.80 \%$ refused to declare if symptoms of pneumonia are discovered, although the majority agreed to report. Nonetheless, considering that any undetected case can result in unpredictable outcomes, this result already deserves great attention. ${ }^{9-11}$

In addition, the results of this study indicated that the rate of adherence to preventive behaviours from COVID-19 was at a desirable level. As shown in figure 2, preventive behaviours such as observing the etiquette of covering the nose or mouth while coughing and sneezing, washing hands, declaring if having a history of close contact with infected persons or history of living in high-risk areas, wearing a mask, avoiding going to the 
affected area, having a good eating habit and working out were at proper levels. Similar results were highlighted by a study in Hong Kong which indicated that more than $77 \%$ of participants reported good health status against COVID-19. ${ }^{12}$

Also, we applied the HBM to predict the likelihood of international students declaring or going for consultation if there are symptoms of COVID-19. Significant differences were found among respondents in health beliefs, cues to action, self-efficacy and paths influencing the likelihood to report or undergo a consultation. We found that perceived susceptibility and barriers only for some items were significant. About $79.83 \%$ disagreed to be more susceptible to get infected. Unlike this study, Kwok et al investigated the early stages of COVID-19 in Hong Kong and found that the individuals had higher perceived susceptibility and severity of COVID-19, so $89 \%$ said that they were at risk of COVID-19 and 97\% said that COVID-19 had severe symptoms. ${ }^{12}$ According to HBM, increased susceptibility to specific health problems will enable the behaviour to reduce its risk of developing health problems. Individuals who think they are at low risk of the disease are more likely to engage in unhealthy or dangerous behaviours. The combination of perceived severity and perceived susceptibility is called perceived threat and depends on knowledge of the condition. ${ }^{13}$ The low level of self-perceived susceptibility $(39.2 \%)$ in this study is a concern. This was not dissimilar to rates in a large pan-European study, where only $31 \%$ of the respondents believed they were at risk of contracting colorectal cancer. ${ }^{14}$ A more impactful method may be through personal encounters for behavioural change.

By discussing the paths of influence in this study, we found the determinants influencing the likelihood of report across the respondents. First, there were different direct or indirect paths of influence between perceived severity and the likelihood of declaring the disease. Apart from being able to test whether one is infected as soon as possible, a more valuable benefit of timely reporting if symptoms of pneumonia are discovered is that it helps to get an early diagnosis and a quick recovery $(\mathrm{p}<0.05)$. The likelihood of reporting was directly influenced by a high perceived severity, but also indirectly, because high perceived severity initiated high cues to action. The results of the present study are similar to results of a study by Powe $e t a l$, which indicated that the perceived severity was an important predictor of corona prevention behaviours in China. ${ }^{15}$ Second, the results of this study reflect that the proportion of the students who recognised these benefits demonstrated a greater willingness to report $(p<0.05)$. Perceived benefits in HBM refer to an individual's assessment of the value or efficacy of engaging in a health-promoting behaviour to decrease risk of the disease. ${ }^{16}$ Additionally, perceived benefits would directly influence the likelihood of reporting or seeking a consultation if symptoms occur. This finding is consistent with prior studies. ${ }^{17}$ In other words, highlighting all the benefits of reporting in public advocacy may be a better option for raising the will to report. Third, perceived barriers refer to an individual's assessment of a behavioural change disorder. ${ }^{16}$ In addition, this outcome is somewhat similar to past study findings which concur that the public fear restrictive epidemic control measures, such as quarantining. ${ }^{16}$ Overall good knowledge about the spread of the disease was very much needed to overcome these barriers. Moreover, international students with symptoms of COVID-19 would generally be subjected to the prevention and control process of quarantine after reporting, until the incubation period passes without any incident. Fear of this has also become one of the factors that impact on the willingness to report. Therefore, effective health education strategies and public risk communication are necessary to eliminate such fear. ${ }^{17}$ In order for behaviour to change, perceived gains must outweigh perceived barriers. ${ }^{16-18}$ Fourth, in investigating the cues that may encourage the student's reporting of symptoms, we found various types of effective cues, with the majority of respondents admitting to the effectiveness of hearing about cases where concealing the illness would result in legal liability that demonstrated a greater willingness to report $(\mathrm{p}<0.05)$. The cues to action include plans by trusted authorities, events or information from intimate others, media or healthcare providers to promote participation in health-related behaviours. ${ }^{16-19}$ To face COVID19, China has implemented the highest level of epidemic prevention and control measures. Therefore, all individuals, including international students, must comply with the epidemiological measures implemented by disease prevention and control institutions and provide relevant information truthfully. Depending on the severity of the results, concealment of the disease will lead to the conviction of the offence of 'endangering public safety by dangerous means'. ${ }^{17-19}$ Self-efficacy is an individual's perception of his or her ability to successfully perform an act. ${ }^{18}$ This produced confidence in the ability to influence outcome change as a key component of healthy behaviour change. ${ }^{18-20}$ This indicates the potential for health education programmes to close the gap by developing effective strategies to persuade people to change their health beliefs, improve self-efficacy and provide meaningful cues to action.

This study adds to our understanding of awareness and promotional activities during pandemics, which will have an impact on pandemic apprehension, knowledge and behaviour.

Furthermore, this study considers how HBM construction during pandemics can help identify and engage in population health promotion behaviours. It will be beneficial to repeat the survey in a few years' time, and review what effect these interventions have had practically on the international students' behaviour during such situation.

Despite this study's findings, we acknowledge its limitations. First, the student's willingness associated with reporting if related symptoms occur may change with the course of the epidemic. A cross-sectional study is limited in its usefulness in capturing this type of dynamic change. 
Future research may consider a longitudinal design. Second, this study only analysed the effects that sociodemographic characteristics and beliefs associated with reporting symptoms had on the willingness to report. There may be other factors affecting the student's willingness to report if symptoms of COVID-19 occur. Third, considering the cost and convenience of conducting research, this study only selectively investigated one province. For more universal results, a study on a larger scale may be necessary. Fourth, the urgency of the situation caused some limitations to the study. The survey was conducted in the early days of COVID-19 pandemic in China, so many students were repatriated to their country, hence the low number of respondents. Potential sample clustering and statistical errors due to multiple significance testing may limit the generalisability of the results.

However, this study has added to the current knowledge of COVID-19. One of the strengths of this study is that it addresses a major health problem. In addition, it has highlighted an area where no research has been done. In fact, this is the first study describing international students' knowledge and beliefs in the various behavioural components of the HBM amid the COVID-19 pandemic. The findings of this study would be critical to design effective control measures in a COVID-19 outbreak.

\section{CONCLUSIONS}

Our study on international students' knowledge and willingness to report if symptoms of COVID-19 occur showed the following findings. First, the level of knowledge is acceptable, however there is still room for improvement in certain areas. Second, this study showed an inclination to withhold symptoms, although in a small proportion $(16.80 \%)$ of the international students. Considering that any incident of withheld symptoms can result in unpredictable outcomes, this finding demands attention. Moreover, our study also indicated that the belief in the benefits of reporting symptoms, the severity of COVID19 , obstacles to reporting and legal consequences of withholding symptoms would affect willingness to report. Therefore, our findings have several important implications for epidemic control. It is necessary to intervene to increase the knowledge of international students toward COVID-19 and to promote the development of healthy behaviours. On the one hand, appropriate public risk communication and public advocacy strategies should be undertaken to assimilate COVID-19-related knowledge, motivation for appropriate practices and further improvement of attitudes towards prevention and control of COVID-19. Specifically, it is important to deepen the understanding that symptom reporting enables individuals and others to be screened and treated for infections as early as possible and to alleviate fears that they may be isolated after reporting. On the other hand, in such crises, international students should not be left out, thus more attention, social support and public awareness campaigns should be enhanced critically.
Author affiliations

${ }^{1}$ Department of Health Policy and Hospital Management, Harbin Medical University, Harbin, Heilongjiang, China

${ }^{2}$ Department of Social Medicine, School of Health Management, Harbin Medical University, Harbin, Heilongjiang, China

${ }^{3}$ The Personnel Department, Harbin Medical University, Harbin, Heilongjiang, China

Acknowledgements We thank all international students for their contribution towards the survey.

Contributors OYI, MJ and QW conceived the study idea and designed the study proposal. OYI collected the data, reviewed transcripts, and coded, analysed, and interpreted the results. YL and ZS contributed to the conception and design of the study, LS and OYI did the statistical analysis and drafted the original manuscript. $\mathrm{LW}, \mathrm{YW}$ and $\mathrm{YL}$ contributed to the analysis, interpretation of data and revising it. YW contributed to the revision of manuscript. OYI, YL and YW contributed equally. $\mathrm{MJ}$ is the guarantor of this study. All authors contributed to data interpretation and rewriting the paper.

Funding This study was funded by the Natural Science Foundation of China (grant nos. 71273002, 71473064), the American Chinese Medical Board (grant no. 19-309) and 2020 Heilongjiang Province Applied Technology Research and Development Plan (grant no. GA20C004).

Disclaimer The funder of the study had no role in study design, data collection, data analysis, data interpretation or writing of the report.

Competing interests None declared.

\section{Patient consent for publication Not required}

Ethics approval This study was approved by the Research and Ethics Committee of Public Health College, Harbin Medical University, Harbin, China (approval number/ ID: HMUIRB20160014). All respondents received a first email before answering the questionnaire, which described the goal and method of the data collection, how the data would be handled and also an assurance of confidentiality. All respondents who gave their informed consent completed the questionnaire. The Research Ethics Committee of Harbin Medical University approved the procedure for obtaining informed consent.

Provenance and peer review Not commissioned; externally peer reviewed.

Data availability statement Data are available upon reasonable request. The data are deidentified participants.

Supplemental material This content has been supplied by the author(s). It has not been vetted by BMJ Publishing Group Limited (BMJ) and may not have been peer-reviewed. Any opinions or recommendations discussed are solely those of the author(s) and are not endorsed by BMJ. BMJ disclaims all liability and responsibility arising from any reliance placed on the content. Where the content includes any translated material, BMJ does not warrant the accuracy and reliability of the translations (including but not limited to local regulations, clinical guidelines, terminology, drug names and drug dosages), and is not responsible for any error and/or omissions arising from translation and adaptation or otherwise.

Open access This is an open access article distributed in accordance with the Creative Commons Attribution Non Commercial (CC BY-NC 4.0) license, which permits others to distribute, remix, adapt, build upon this work non-commercially, and license their derivative works on different terms, provided the original work is properly cited, appropriate credit is given, any changes made indicated, and the use is non-commercial. See: http://creativecommons.org/licenses/by-nc/4.0/.

\section{ORCID iDs}

Omar Yacouba Ismael http://orcid.org/0000-0002-7925-0912

Mingli Jiao http://orcid.org/0000-0001-7405-5571

Ye Li http://orcid.org/0000-0001-8492-1808

\section{REFERENCES}

1 Jones CL, Jensen JD, Scherr CL, et al. The health belief model as an explanatory framework in communication research: exploring parallel, serial, and moderated mediation. Health Commun 2015;30:566-76.

2 Champion VLet al. The health belief model 2008;4:45-65.

3 Carico RR, Sheppard J, Thomas CB. Community pharmacists and communication in the time of COVID-19: applying the health belief model. Res Social Adm Pharm 2021;17:1984-7. 
4 Sun T, Wang Y. Modeling COVID-19 epidemic in Heilongjiang Province, China. Chaos Solitons Fractals 2020;138:109949.

5 Lu Y, Zhang L. Social media WeChat infers the development trend of COVID-19. J Infect 2020;81:e82-3.

6 Brug J, Aro AR, Oenema A, et al. Sars risk perception, knowledge, precautions, and information sources, the Netherlands. Emerg Infect Dis 2004;10:1486-9.

7 Zhang M, Zhou M, Tang F, et al. Knowledge, attitude, and practice regarding COVID-19 among healthcare workers in Henan, China. $J$ Hosp Infect 2020;105:183-7.

8 McEachan R, Taylor N, Harrison R, et al. Meta-Analysis of the reasoned action approach (RAA) to understanding health behaviors. Ann Behav Med 2016;50:592-612.

9 Lipsitch M, Cohen T, Cooper B, et al. Transmission dynamics and control of severe acute respiratory syndrome. Science 2003;300:1966-70.

10 Riley S, Fraser C, Donnelly CA, et al. Transmission dynamics of the etiological agent of SARS in Hong Kong: impact of public health interventions. Science 2003;300:1961-6.

11 Breban R, Riou J, Fontanet A. Interhuman transmissibility of middle East respiratory syndrome coronavirus: estimation of pandemic risk. Lancet 2013;382:694-9.
12 Kwok KO, Li KK, Chan HHH, et al. Community responses during early phase of COVID-19 epidemic, Hong Kong. Emerg Infect Dis 2020;26:1575-9.

13 Rosenstock IM. Historical origins of the health belief model. Health Educ Monogr 1974;2:328-35.

14 Keighley MRB, O'Morain C, Giacosa A, et al. Public awareness of risk factors and screening for colorectal cancer in Europe. Eur $J$ Cancer Prev 2004;13:257-62.

15 Powe BD. Cancer fatalism among elderly African American women. $J$ Psychosoc Oncol 2001;19:85-95.

16 Janz NK, Becker MH. The health belief model: a decade later. Health Educ Q 1984;11:1-47.

17 Wei L, Sha Z, Wang Y, et al. Willingness and beliefs associated with reporting travel history to high-risk coronavirus disease 2019 epidemic regions among the Chinese public: a cross-sectional study. BMC Public Health 2020;20:1-9.

18 Glanz K, Rimer BK, Viswanath K. Health behavior and health education: theory, research, and practice. John Wiley \& Sons, 2008.

19 Albashtawy M, Gharaibeh H, Alhalaiqa F, et al. The health belief model's impacts on the use of complementary and alternative medicine by parents or guardians of children with cancer. Iran $J$ Public Health 2016;45:708-9.

20 Rosenstock IM, Strecher VJ, Becker MH. Social learning theory and the health belief model. Health Educ Q 1988;15:175-83. 